\title{
Tradição e conhecimento, ou a vida ao ar livre - apresentação à tradução
}

\author{
DANIEL BELIK
}

MARIANA CLAVATTA PANTOJA

Depois de arrefecidas as discussões sobre caçadores-coletores, humanidade-animalidade, ecologia e evolução travadas com a antropologia de Manchester na década de 80, Tim Ingold estabelece-se definitivamente como referência teórica ao organizar a Companion Encyclopedia of Anthropology: Humanity, Culture and Social Life (1994). Logo depois veio Key Debates in Anthropology (1996), que recolocou no radar da disciplina temas ainda hoje discutidos, como a capacidade de generalização da antropologia social, e conceitos como "sociedade", "linguagem", "mundo humano" e "estética". Seu trabalho, contudo, só passa a ser largamente difundido no Brasil a partir da publicação de The Perception of the Environment (2000)1. Na década seguinte, estudantes de antropologia, arquitetura, artes, arqueologia e pedagogia brasileiros e de vários países da América Latina (principalmente Argentina, Uruguai, Chile e Colômbia) já estavam estudando ou fazendo intercâmbio, sob supervisão de Ingold, no recém-criado departamento de antropologia da Universidade de Aberdeen, na Escócia. Principalmente depois de sua passagem pelo Uruguai e pelo Brasil, em 2011, ocasião em que visitou a UDELAR, a UFRGS, a UNB e a UFMG, vários materiais de sua autoria e a partir de sua obra começam a ser traduzidos e/ou publicados em português e espanhol².

1 Ou apenas Perception, como iremos nos referir aqui a esta obra, lamentavelmente, até o momento, ainda sem tradução para o português. Podemos talvez dizer que o fechamento de um ciclo do Perception se deu em 2015, com o simpósio Beyond Perception, que aconteceu em Aberdeen com a participação de diversos acadêmicos visando avaliar o desempenho daquela obra desde sua publicação

2 Alguns exemplos são as traduções dos livros de Ingold "Evolution and Social Life" (1986), "Lines" (2007) e "Being Alive" (2011), e dos seus artigos: "What is an Animal?" (1988), "Humanity and Animality" (1994), "From Complementarity to Obviation: On Dissolving the Boundaries between Social and Biological Anthropology, Archaeology and Psychology" (1998), "Three in One" (1999), "From the transmission of representations to the education of attention" (2001), "On the Distinctions between Evolution and History" (2002), "Materials against Materiality" (2007), "Bringing Things to Life: Creative Entanglements in a World of Materials" (2010), "Dreaming of Dragons: on the imagination of real life" (2013), "That's enough about ethnography!" (2014), "The maze and the labyrinth: walking, imagining and the education of attention" (2015), "Anthropology contra ethnography" (2017) e dos capítulos 13, 14 e 21 do Perception (2000): "To Journey along a way of life: maps, wayfinding and navigation", "Stop, Look, Listen!" e "People like us: the concept of the anatomically modern human”, respectivamente. Na bibliografia ao final dessa apresentação podem ser encontradas referências dos artigos e livros já traduzidos para o português e o espanhol. 
Ainda assim, talvez haja mais ainda a ler ou descobrir a partir do Perception.

$\mathrm{Na}$ tradução a seguir, de um artigo contemporâneo a esta obra e escrito em coautoria com uma antropóloga "nativa” da região ártica, buscamos continuar a dar visibilidade às questões propostas pelo autor. Neste texto de apresentação, nosso objetivo é chamar atenção para algumas reflexões que a leitura de uma etnografia nórdica ${ }^{3}$ suscitou em nós, amazônidas.

A decisão de traduzir este artigo nasceu num contexto de leitura, sem um roteiro muito definido, de alguns textos de Ingold; os interesses e acúmulos sobre a obra do autor eram um pouco diversos, e assim fomos negociando nosso percurso ao longo do caminho. Encontramos a referência ao artigo aqui traduzido num capítulo de Being Alive em que Ingold argumenta contra a noção de espaço por sua tendência de enclausuramento da "vida" - este que é um conceito crucial, para não dizer vital, na antropologia por ele defendida. Tal enclausuramento tem suas raízes no que ele chama de "lógica da inversão": a ideia de que sistemas locais de conhecimento não seriam a expressão do envolvimento das pessoas no mundo, mas ao contrário, seriam transmitidos já prontos de geração em geração (Ingold 2011:155).

Neste sentido, a primeira ideia a ressaltar no artigo de Ingold e Kurtilla é a de genealogia, ou "modelo genealógico", à qual os autores se opõem com veemência, pode-se dizer, em sua discussão sobre o sentido da ideia de cultura e do ato de conhecer. Para eles, o repertório de saberes e fazeres que configuram uma cultura, ou uma herança cultural, não podem estar presos, como se supõe, a um passado tal como numa linha de descendência genética. Esse análogo ao genótipo, apelidado de "culturótipo", é a crença de que informação é passada nessas linhas de transmissão (Ingold, 2007: 115). No Perception, Ingold já denunciara este divórcio operado pelo modelo genealógico entre a aquisição de conhecimento e as experiências ambientalmente situadas de que se constituem a vida das pessoas (Ingold, 2000: 138). A etnografia apresentada por Ingold e Kurtilla mostra claramente como as pessoas se dão conta do que fazem "perambulando", ou se movimentando pelo ambiente.

As consequências do que foi dito são enormes. Ingold prefere se referir a um conhecimento "estoriado" ou "narrativo" (storied knowledge), em oposição a um conhecimento "classificatório" (2015 [2011]). Aquele articula noções-chaves no pensamento ingoldiano, como lugar, movimento e conbecimento que, por sua vez, apontam não para conceitos e relações independentes do contexto, mas para nós ou nódulos de ocorrências gerados pelos caminhos da vida. Estas noções, será visto, encontram-se operacionalizadas no artigo de Ingold e Kurtilla. Podemos mesmo dizer que este artigo é a primeira tentativa de Ingold de experimentação com a ideia de weather, ou seja, de mostrar que a vida é vivida ao longo de um mundo em formação onde os grupos locais orientam-se pelas estações do ano, valen-

3 Desde 2013, Ingold coordena o projeto Knowing from the inside: antropology, art, architecture and design e o Grupo de Estudos do Norte (The North), na Universidade de Aberdeen, que desenvolve pesquisas sobre a Finlândia, a Lapônia, a Europa do Norte e o Circumpolar Norte.

4 Em 1910, um artigo de W.H.R Rivers trouxe o método do modelo genealógico para a Antropologia e estabeleceu uma separação entre as histórias contadas pelas pessoas sobre elas mesmas e as informações obtidas delas mediante análise cientifica sistemática. Quase que imperceptivelmente, mostrou Ingold no Perception (p. 138), a diferença foi transformada em diversidade integrada verticalmente - de descendentes para baixo e ancestrais para cima -, comparando indivíduos com base nas características que eles possuíam, descartando as eventuais relações que eles travassem uns com os outros. 
do-se de sua habilidade de perceber as menores mudanças de tempo (weather) (Ingold 2008: 1803). Esta habilidade é conceituada por Ingold como skill, um conhecimento desenvolvido e transmitido no fazer, e por isso também secreto, subterrâneo, irrevelável. Os velhos têm mais conhecimento não porque acumularam mais informação durante a vida, mas porque por meio das atividades que executaram sua sensibilidade para os sinais do meio ambiente foram desenvolvidas, assim como sua capacidade de responder a esses sinais com bom-senso e precisão (Ingold 2015 [2011]: 238).

O caminho para esta abordagem, tal como trabalhada por Ingold e Kurtilla, foi uma pesquisa com os Sami - agricultores e pastores da Lapônia finlandesa - sobre seu ambiente, em particular sobre as mudanças que percebiam e se estas poderiam se constituir em indicadores de "mudanças climáticas", ao lado dos já estabelecidos pela ciência. Em sua investigação, Ingold e Kurttila encontraram que as mudanças percebidas são narradas não como alterações "climáticas" (comumente identificadas por índices tais como temperatura, precipitação, etc), mas sim como experiências e memórias relativas a atividades comumente realizadas ou a momentos cruciais da vida coletiva (como nascimentos e mortes), e que esse conhecimento estava ainda diferencialmente distribuído intergeracionalmente e entre homens e mulheres, engajados que estão em tarefas diferentes. Os autores observaram o quanto os cinco sentidos funcionam como órgãos da percepção e, enquanto tais, importantes ferramentas de conhecimento. "Percebe-se, com efeito, com todo o corpo", dizem Ingold e Kurttila. Esta atenção multissensorial, por exemplo, permite aos Sami, em suas diferentes andanças e atividades, orientarem-se com mais segurança e eficácia. Nos momentos em que o ambiente silencia, como antes de uma tempestade, há incerteza e insegurança, pois não há com o que sintonizar — sendo este verbo o próprio significado do "mover-se num ambiente".

O conhecimento tradicional, seguindo a maneira local de descrever os processos de vir a conhecer, se referiria, portanto, a "uma propriedade de todo o organismo-pessoa humana"; realizar-se-ia enquanto tal ao longo da história de envolvimento prático das pessoas com um ambiente; e seria contínuo, isto é, sempre em "geração e regeneração", o que, por sua vez, seria perfeitamente compatível com a ideia de uma tradição que atravessa o tempo sem adquirir uma forma fixa e imobilizadora. A questão é relevante, e, para os Sami, urgente, já que enfrentavam, à época de publicação do artigo, questionamentos típicos do pensamento genealógico com relação a autenticidade de suas práticas culturais. Sob o risco da perda de direitos territoriais, estava sendo deles exigido que formulassem sua tradição de uso da terra em termos de regras e princípios inteligíveis pela lógica da descendência ou herança, no caso cultural. A definição dos Sami de que sua tradição é "a forma como fazemos as coisas aqui" - afirmação cujas consequências teóricas serão exploradas no artigo de Ingold e Kurtilla — é inaceitável para a ideia de conhecimento tradicional produzida pelo discurso moderno, impregnado que está justamente pelo modelo genealógico.

A partir, portanto, da crítica feita ao modelo genealógico de pensamento, e da etnografia apresentada pelos autores, torna-se impossível pensar a tradicionalidade de um conhecimento com base na ideia de que haveria um corpus de conceitos e práticas, aplicado ou dito, replicado de geração em geração como um legado do passado, antes e independente da existência das pessoas. Ao contrário, este cor- 
pus é gerado nos contextos da atividade presente, na interação entre pessoas e seus ambientes de vida. Como Ingold já deixara claro em Perception, as pessoas são educadas com base em um processo de vida.

Isto posto, é inevitável perguntar-se sobre o que seriam "conhecimentos tradicionais", tema tão caro aos "povos e comunidades tradicionais" de todo Brasil, e da Amazônia em especial. Trata-se daquele conjunto de saberes e práticas herdado dos antepassados e conservado por seus descendentes? De um repertório culturalmente diferenciado cujos laços de origem constituem uma espécie de marca distintiva do grupo e de seu modo de vida? A contribuição de Ingold (e Kurtilla) a esta discussão estaria justamente no papel desempenhado pelo ambiente de vida das pessoas no processo (pois é disto que se trata) de constituição do conhecimento local e sua tradicionalidade. Neste sentido, o que será que está em curso em lugares como, por exemplo, o Parque Indígena do Xingu, onde parece não ser mais possível guiar-se pelos sinais da natureza, ou melhor, onde estes sinais talvez estejam se tornando ininteligíveis?5 Que transformações estão em curso nas formas locais de percepção e elaboração do conhecimento?

É seguindo esta linha de raciocínio que os autores vão trazer à tona e criticar a prioridade que a Convenção 169, da OIT, concede ao critério da descendência na definição de uma pessoa como "indígena”. Algo interno, sobre o qual a pessoa não tem nenhum controle ou agência, a definiria; ela não precisaria fazer nada para ser indígena, nem mesmo viver em sua terra. Talvez este seja o ponto mais delicado do texto, em especial quando pensamos no contexto de demandas por direitos e reconhecimento por parte dos povos indígenas brasileiros. Mas o que Ingold e Kurtilla querem denunciar é a armadilha do modelo genealógico, que tira a vida presente e vivida de cena em troca de imagens, relatos e relações pré-definidas. Não estarão muitos grupos locais presos nesta armadilha quando lhes é imputado a denominação de "tradicionais", e se veem obrigados a uma série de regras e deveres "de fora" para permanecer em seus territórios, agora recobertos por Unidades de Conservação?

O exemplo dos Sami alerta para um tipo de engessamento que ameaça a tradição tal como reconhecida e vivida pelo grupo. Na tradução que ora apresentamos, Ingold e Kurtilla propõem justamente uma abordagem dos conhecimentos tradicionais que, como dizem, "soe mais consonante com as sensibilidades locais".

\author{
Daniel Belike é doutor em Antropologia Social pela Universidade de St. Andrews \\ (Grä-Bretanha) e atualmente professor substituto na Universidade Federal do \\ Acre (UFAC).
}

\title{
Mariana Pantoja Franco é doutora em Antropologia Social pela UNICAMP e professora de Antropologia na Universidade Federal do Acre (UFAC).
}

\footnotetext{
5 A referência aqui é o minidocumentário "Antes da Chuva" (Rede de Sementes do Xingu e ISA, 2018), disponível na internet, e que registra a percepção de jovens agricultores e indígenas do Xingu e Araguaia dos efeitos das "mudanças climáticas" em suas vidas e cotidiano de trabalho.

6 Ver, por exemplo, o trabalho de Prado (2012), que discute o conceito de "populações tradicionais" assumindo justamente a perspectiva defendida por Ingold e Kurtilla.
} 


\section{REFERÊNCIAS BIBLIOGRÁFICAS}

INGOLD, Tim. 1991. Evolución y vida social. México: Grijalbo.INGOLD, Tim (ed.). 1994. Companion encyclopedia of anthropology: humanity, culture and social life. London: Routledge. 1995. Humanidade e animalidade. RBCS (28): 39-53. 1996. Key debates in anthropology. London: Routledge. 2000. The perception of the environment: essays on livelihood, dwelling and skill. London: Routledge.

. 2006. “Sobre a distinção entre evolução e história”. Antropolitica (20): 11-16. 2007. “Introdução. O que é um animal?”. Antropolitica (22): 129-150.

2008a. Pare, olhe, escute! - um prefácio. São Paulo. Ponto Urbe [Online], 3. https:// journals.openedition.org/pontourbe/1944 (Acesso em 10/07/2018)

.2008b. "Tres en uno: cómo dissolver las distinciones entre mente, cuerpo y cultura". In: Sánchez-Criado, T. (org.). Tecnogénesis: la construcción técnica de las ecologías humanas (Vol. 2). Madrid: Antropólogos Iberoamericanos en Red.

.2008c. "Bindings against boundaries: entanglements of life in an open world". Environment and Planning (40): 1796-1810.

. 2010. “Da transmissão de representações à educação da atenção". Educação (1): 6-25. .2011. 'Gente como a gente.' O conceito de homem anatomicamente moderno. São Paulo. Ponto Urbe [Online], 9. https://journals.openedition.org/pontourbe/1823 (Acesso em 10/07/2018) .2012a. "Trazendo as coisas de volta a vida: emaranhados criativos num mundo de materiais”. Horizontes Antropológicos (37): 25-44.

.2012b. “Caminhando com dragões: em direção ao lado selvagem”. In: PRADO, Rosane M. 2012. "Viagem pelo conceito de populações tradicionais, com aspas”. In: STEIL, Carlos A. \& CARVALHO, Isabel C. de M. (orgs.). Cultura, percep̧̧ão e ambiente: diálogos com Tim Ingold. São Paulo: Editora Terceiro Nome.

STEIL Carlos A. \& CARVALHO, Isabel C. de M. (orgs.). Cultura, percepção e ambiente: diálogos com Tim Ingold. São Paulo: Editora Terceiro Nome.

. 2013. "Los materiales contra la materialidade". Papeles de Trabajo (11): 19-39. .2015a. "Desde la complementariedad a la obviación: sobre la disolución de los límites entre la antropología social, biológica, arqueología y psicologia”. AVÁ Revista de Antropología (26): 12-51. .2015b. Lineas: una breve historia. Barcelona: Gedisa. .2015c. Estar vivo: ensaios sobre movimento, conhecimento e descrição. Petrópolis:

Editora Vozes.

.2015d. "O dédalo e o labirinto: caminhar, imaginar e educar a atenção". Horizontes Antropológicos (44): 21-36.

.2016. "Chega de etnografia! A educação da atenção como propósito da antropologia”. Educação (3): 404-11. 
2017. "Antropologia versus etnografia". Cadernos de Campo (26): 223-229.

. s/d. Jornada ao longo de um caminho de vida - mapas, descobridor-caminho e navega-

ção. Mimeo.

RECEBIDO: $10 / 07 / 2018$

APROVADO: $12 / 07 / 2018$ 